\title{
ESTIMATION OF THE EFFECTIVE SPREAD OF NEURAL EXCITATION PRODUCED BY A BIPOLAR PAIR OF SCALA TYMPANI ELECTRODES
}

\author{
Y. C. Tong, BE, PhD; G. M. Clark, PhD, FRACS; H. H. Lim, BE, BSC
}

Psychophysical studies were conducted on two multichannel cochlear implant patients for electrical stimulation of two bipolar electrode pairs in the human cochlea. Loudness summation was approximately complete for spatial separation of about $3 \mathrm{~mm}$ between the two electrode pairs. At comfortable loudness, the effective spread of neural excitation produced by a bipolar pair of scala tympani electrodes was estimated to be 3 to $4 \mathrm{~mm}$ on the basis of both loudness summation and forward masking results.

This paper supplements a previous report on loudness summation and forward masking. ${ }^{1}$ Experimental procedures and results for both studies were described in detail in the original report. This paper aims to estimate the effective spread of neural excitation distribution at comfortable loudness produced by a bipolar pair of scala tympani electrodes.

\section{LOUDNESS SUMMATION}

Figure 1A shows two electrode pairs, EP-A and EP-B, each producing half-comfortable loudness when activated in isolation. The spatial separation between the two electrode pairs was $3 \mathrm{~mm}$. The overall loudness produced by activating both electrode pairs in quick succession within a stimulus period was comfortable because loudness summation was complete at a spatial separation of about $3 \mathrm{~mm}{ }^{1}$

This behavior can be explained by the simplified models depicted in Fig 1B,C. The neural excitation distribution produced by activating an electrode pair in isolation is assumed to be approximately trapezoidal. Figure 1B shows the neural excitation distribution produced by activating the two electrode pairs in quick succession as a combined stimulus. Figure lC shows the neural excitation distribution produced by activating a reference or standard electrode pair also of comfortable loudness. Although the distributions in Fig 1B,C are significantly different, they correspond to the same comfortable loudness.

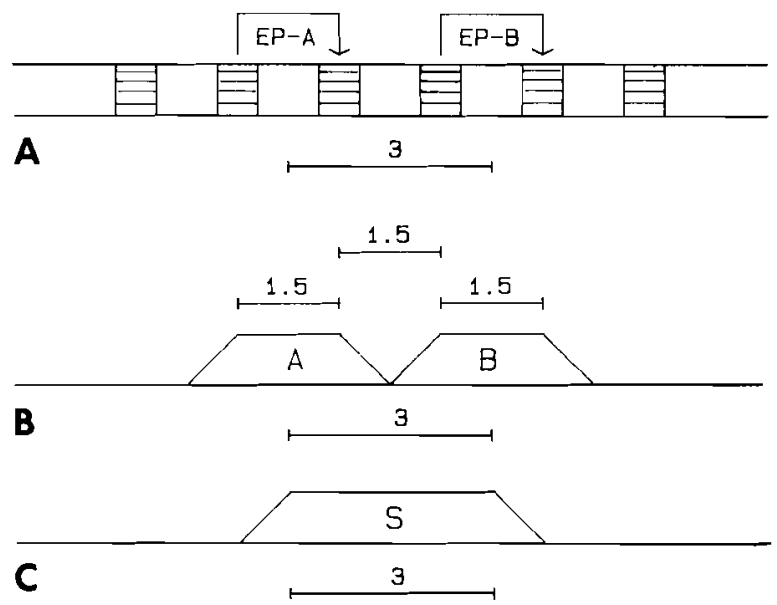

Fig 1. A) Two electrode pairs, each of half-comfortable loudness, activated as combined stimulus. B, C) Neural excitation distribution produced by combined stimulus at comfortable loudness (B), and by standard stimulus at comfortable loudness $(\mathrm{C})$. All dimensions are given in millimeters.
The neural excitation distribution for the combined stimulus (Fig $\mathrm{lB}$ ) is assumed to have the dimensions as shown. It is further assumed that a significantly large proportion of the loudness produced by activating an electrode pair is primarily caused by the saturated region or the flat top of the trapezoidal neural excitation distribution. Loudness summation is complete at $3 \mathrm{~mm}$ spatial separation because there is very little interaction between the two neural distributions depicted in Fig 1B.

From Fig $1 \mathrm{~B}$ the effective spread of the neural excitation distributions for the combined stimulus can be estimated to be approximately $1.5+1.5$ or $3 \mathrm{~mm}$. Because the loudness produced by the combined stimulus (Fig $1 \mathrm{~B}$ ) is equal to the loudness produced by the standard electrode pair, the effective spread of the neural excitation for the standard electrode pair (Fig 1C) would also be about $3 \mathrm{~mm}$. This led to the estimation that the spread of the neural excitation for comfortable loudness is on the order of about 3 to $4 \mathrm{~mm}$ for a bipolar pair of electrodes in the scala tympani.

\section{FORWARD MASKING}

Figure 2 shows the results for the forward masking study. Details of the experimental procedures were described in the original paper. ${ }^{1}$ In this experiment the loudness produced by the masker electrode pair was comfortable to the patient.

The amount of masking remained relatively constant for spatial separations below $1.5 \mathrm{~mm}$ before decreasing significantly with spatial separation. Note that this forward masking result only reveals one half of the profile of the neural excitation distribution produced by the masker electrode pair. Assuming symmetry, the saturated region

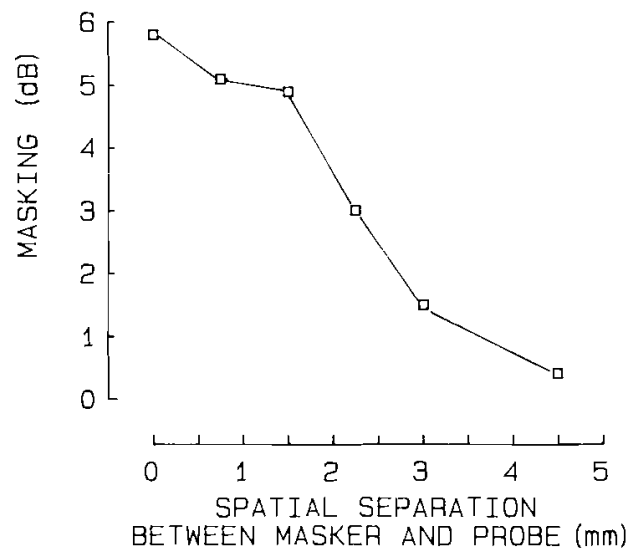

Fig 2. Results of forward masking studies. 
of the neural excitation distribution produced by the masker electrode pair would be $3 \mathrm{~mm}$ and the shape of the neural excitation distribution would be approximately trapezoidal. These support the assumptions of the models in Fig 1 and agree with the results obtained in the loudness summation study.

\section{REFERENCE}

1. Tong YC, Clark GM. Loudness summation, masking and temporal interaction for sensations produced by electric stimulation of two sites in the human cochlea. J Acoust Soc Am 1986;79: 1958-66. 


\section{University Library}

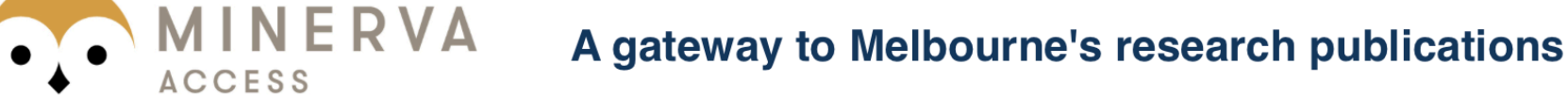

Minerva Access is the Institutional Repository of The University of Melbourne

Author/s:

Tong, Y. C.; Clark, Graeme M.;Lim, H. H.

Title:

Estimation of the effective spread of neural excitation produced by a bipolar pair of scala tympani electrodes

Date:

1987

\section{Citation:}

Tong, Y. C., Clark, G. M., \& Lim, H. H. (1987). Estimation of the effective spread of neural excitation produced by a bipolar pair of scala tympani electrodes. Annals of Otology, Rhinology \& Laryngology, January-February, 96(1, part 2, suppl.128), 37-38.

Persistent Link:

http://hdl.handle.net/11343/27257 